Article

\title{
Antibacterial and Biodegradable Electrospun Filtering Membranes for Facemasks: An Attempt to Reduce Disposable Masks Use
}

\author{
Sofia M. Costa ${ }^{1}$, Luísa Pacheco ${ }^{1}$, Wilson Antunes ${ }^{2}$, Ricardo Vieira ${ }^{2}$, Nuno Bem ${ }^{2}$, Pilar Teixeira ${ }^{3}$, \\ Raul Fangueiro ${ }^{1,4}\left(\mathbb{D}\right.$ and Diana P. Ferreira ${ }^{1, *}$ (D) \\ 1 Centre for Textile Science and Technology (2C2T), University of Minho, 4800-058 Guimarães, Portugal; \\ sofiamcosta@det.uminho.pt (S.M.C.); pg41793@alunos.uminho.pt (L.P.); rfangueiro@dem.uminho.pt (R.F.) \\ 2 Centro de Investigação da Academia Militar (CINAMIL), Unidade Militar Laboratorial de Defesa Biológica e \\ Química (UMLDBQ, Instituto Universitário Militar), Av. Dr. Alfredo Bensaúde, 1849-012 Lisboa, Portugal; \\ antunes.wdt@exercito.pt (W.A.); ricardojsilvavieira@gmail.com (R.V.); nuno_bem@hotmail.com (N.B.) \\ 3 CEB-Centre of Biological Engineering, University of Minho, 4710-057 Braga, Portugal; pilar@ceb.uminho.pt \\ 4 Department of Mechanical Engineering, University of Minho, 4800-058 Guimarães, Portugal \\ * Correspondence: diana.ferreira@det.uminho.pt
}

Citation: Costa, S.M.; Pacheco, L.; Antunes, W.; Vieira, R.; Bem, N.;

Teixeira, P.; Fangueiro, R.; Ferreira, D.P. Antibacterial and Biodegradable Electrospun Filtering Membranes for Facemasks: An Attempt to Reduce Disposable Masks Use. Appl. Sci. 2022, 12, 67. https://doi.org/ 10.3390/app12010067

Academic Editors: Diana Ferreira, Raul Fangueiro and

Seeram Ramakrishna

Received: 3 December 2021

Accepted: 17 December 2021

Published: 22 December 2021

Publisher's Note: MDPI stays neutral with regard to jurisdictional claims in published maps and institutional affiliations.

Copyright: () 2021 by the authors. Licensee MDPI, Basel, Switzerland. This article is an open access article distributed under the terms and conditions of the Creative Commons Attribution (CC BY) license (https:// creativecommons.org/licenses/by/ $4.0 /)$.

\begin{abstract}
Due to the prevalence of the COVID-19 pandemic, the demand for disposable facemasks has become a global issue. Unfortunately, the use of these products has negative effects on the environment, and therefore, the use of biodegradable materials is a powerful strategy to overcome this challenge. Aligned with this concept, in this work, biodegradable facemasks were developed using poly( $\varepsilon$-caprolactone) (PCL) polymer and cotton natural fibers. The filter layer was produced using an electrospinning technique, since electrospun membranes present remarkable characteristics for air filtration. The electrospun membranes were functionalized with different nanoparticles (NPs), including silver $(\mathrm{Ag})$, titanium dioxide $\left(\mathrm{TiO}_{2}\right)$ and magnesium oxide $(\mathrm{MgO})$, in order to include new properties, namely antibacterial effect. The developed membranes were characterized by FESEM, EDS, ATR-FTIR, GSDR and TGA, which confirmed the successful impregnation of NPs onto PCL membranes. The antibacterial effect and filtration efficiency were assessed, with the PCL/MgO NPs membrane presenting better results, showing inhibition zone diameters of 25.3 and $13.5 \mathrm{~mm}$ against Gram-positive and Gram-negative bacteria, respectively, and filtration efficiency of $99.4 \%$. Three facemask prototypes were developed, and their filtration efficiency, air permeability and thermal comfort were evaluated. Overall, this study demonstrates the potential of PCL/NPs electrospun membranes to act as an active and biodegradable filter layer in facemasks.
\end{abstract}

Keywords: electrospun membranes; nanoparticles; biodegradable polymers; natural fibers; facemask; antibacterial effect; filtration efficiency

\section{Introduction}

The sudden outburst of the COVID-19 pandemic, caused by severe acute respiratory syndrome coronavirus 2 (SARS-CoV-2), has contributed to the extensive production and consumption of facemasks worldwide, creating a new and serious environmental challenge. Facemasks are generally composed of nonbiodegradable polymers, such as polypropylene, polyethylene, polyurethane, polystyrene, polycarbonate and polyacrylonitrile, and the disposal of these facemasks generates a large amount of waste, causing severe ecological problems and becoming a new source of microplastics [1,2].

Therefore, researchers have been looking for innovative strategies to develop facemasks with a similar or better performance to the existing nonbiodegradable ones, to minimize the negative environmental impact. One sustainable option is the exploitation of green chemistry as well as the replacement of conventional materials with eco-friendly ones, such as natural fibers and biodegradable polymers [2-4]. 
Recently, the electrospinning technique has acquired tremendous focus for the development of high-performance filters. This technique enables the production of fibers with diameters ranging from micrometers to nanometers, which show significant morphological advantages over current conventional filters. Moreover, the cost effectiveness, simplicity of use, versatility of using different biodegradable natural or synthetic materials and possibility of scalability make electrospinning more competitive and attractive compared to conventional nonwoven manufacturing methods [5,6]. In fact, electrospun fibers exhibit outstanding properties, such as a high specific surface area, which results in the higher adsorption capacity of contaminants, controllable small diameters, highly porous structure with small pore sizes and internal interconnectivity, flexibility and possibility of functionalization with active agents. Due to their low weight and high permeability, these fibrous membranes provide high filtration efficiency, without adding extra weight and maintaining the wearer's comfort and breathability [7-10].

To date, several polymers have been used to produce membranes by electrospinning for air filtration applications. As already mentioned, to face the accumulation of plastics in the environment, the use of biodegradable polymers is preferable [4]. Among them, synthetic PCL polymer has been demonstrated as a promising candidate for filtration applications, due to its low cost, biocompatibility, biodegradability, availability, excellent mechanical properties and ease of operation [11-13].

Besides acting as a physical barrier to prevent the penetration of small particles and microorganisms, electrospun membranes can be functionalized with several materials in order to achieve new functions, such as antimicrobial activity. Microorganisms can reach the surface of the mask, fail to be destroyed and then penetrate the filter layer, which compromises the protection of the wearer. Therefore, the development of facemasks able not only to act as a barrier for the particles and microorganisms but also to actively degrade them is crucial [14].

One possible approach to develop active filter layers is by the addition of antimicrobial agents, such as NPs. Their nanoscale size and large surface area-to-volume ratio give NPs unique characteristics, improving their catalytic, magnetic, mechanical and optical properties $[15,16]$. Several metal and metal oxide NPs, such as $\mathrm{Ag}, \mathrm{TiO}_{2}$ and $\mathrm{MgO}$, have been explored as effective antimicrobial agents against several microorganisms, such as bacteria, viruses and fungi $[17,18]$. With the increasing concern about bacterial resistance, other alternatives to the use of antibiotics are required. In this way, NPs arise as suitable options since their mechanisms of action are different from traditional antibiotics $[19,20]$. Furthermore, $\mathrm{Ag}$ [21], $\mathrm{TiO}_{2}$ [22] and $\mathrm{MgO}$ [23] NPs are already shown to increase the filtration efficiency of electrospun membranes. Therefore, the combination of antimicrobial NPs with electrospun membranes is a very promising strategy to improve the overall performance of the facemasks, namely the filtration efficiency as well as elimination of microorganisms $[5,18,22]$.

The incorporation of the materials into electrospun fibers can be carried out using different techniques, namely the surface functionalization. In this method, the electrospun membranes are firstly produced, and then functionalized with the desirable materials in order to obtain improved properties. Using the surface functionalization method, the NPs stay available at the surface of the fibers instead of within them [24]. This also reduces the costs compared to the conventional inclusion approaches, due to the use of fewer nanomaterials for an equivalent efficacy and fine-tuning of surface properties [25].

Thus, the aim of this work involves the development of an active, fully biodegradable facemask which is able not only to exhibit high filtration efficiency but also to degrade the microorganisms, taking advantage of the biodegradability and excellent properties of natural fibers and biopolymers. The first part of the work was focused on the development of PCL electrospun membranes functionalized with different types of $\mathrm{NPs}\left(\mathrm{Ag}, \mathrm{TiO}_{2}\right.$ and $\mathrm{MgO}$ ) to act as the filter layer. Ag NPs were synthetized using a green methodology, whereas commercial $\mathrm{TiO}_{2}$ and $\mathrm{MgO}$ NPs were used. All the developed membranes were characterized by Field Emission Scanning Electron Microscopy (FESEM), Energy Dispersive 
Spectroscopy (EDS), Attenuated Total Reflectance-Fourier Transform Infrared Spectroscopy (ATR-FTIR), Ground State Diffuse Reflectance (GSDR) and Thermogravimetric Analysis (TGA). The functional properties were also evaluated, including the antibacterial activity and the filtration efficiency. Finally, the PCL/NPs electrospun membranes with the most promising results were selected for the production of a facemask prototype, using cotton natural fiber for the inner and outer mask layers. Three different configurations of facemasks were evaluated regarding their filtration efficiency, air permeability and thermal comfort.

\section{Materials and Methods}

\subsection{Materials}

PCL pellets (molecular weight of 80,000 g/mol) were purchased from Sigma Aldrich. Chloroform (CHF) and N,N-Dimethylformamide (DMF) were provided by Honeywell and Sigma Aldrich, respectively. Commercial $\mathrm{NPs}\left(\mathrm{TiO}_{2}\right.$ and $\left.\mathrm{MgO}\right)$ were acquired from Sigma Aldrich. For the synthesis of Ag NPs, silver nitrate $\left(\mathrm{AgNO}_{3}\right)$ and poly(ethyleneglycol) (PEG) $\mathrm{Mr} \sim 200$ were provided by Scharlau.

\subsection{Preparation of PCL Polymer Solution}

PCL polymer solutions were prepared according to the procedure described by Francavilla et al. [13], using 15\% (w/v) of PCL in CHF/DMF (4:1). Firstly, PCL pellets were dissolved in $\mathrm{CHF}$ and stirred at $35^{\circ} \mathrm{C}$ for at least $2 \mathrm{~h}$, until their complete dissolution. Afterwards, DMF was added to the polymer solution and left under stirring overnight.

\subsection{Electrospinning Process}

PCL solution was electrospun in electrospinning NF-103 equipment from MECC Co., Ltd. (Fukuoka, Japan). The polymer solution was transferred into a $24 \mathrm{~mL}$ syringe accoupled to a needle with diameter of $0.61 \mathrm{~mm}$. A static metallic collector was used to collect the electrospun membranes. The final processing conditions used to produce defect-free fibers are shown in Table 1.

Table 1. Processing parameters used to produce electrospun membranes.

\begin{tabular}{cc}
\hline Processing Parameters & Optimized Values \\
\hline Applied voltage & $25 \mathrm{kV}$ \\
Feed rate & $1 \mathrm{~mL} / \mathrm{h}$ \\
Needle-to-collector distance & $260 \mathrm{~mm}$ \\
Needle diameter & $0.61 \mathrm{~mm}$ \\
Deposition time & $4 \mathrm{~h}$ \\
Head transverse speed & $50 \mathrm{~mm} / \mathrm{s}$ \\
Head transverse distance & $150 \mathrm{~mm}$ \\
Type of collector & Static \\
Humidity & $59-65 \%$ \\
Temperature & $19-20^{\circ} \mathrm{C}$ \\
\hline
\end{tabular}

\subsection{Functionalization of PCL Electrospun Membranes with NPs}

After the production of PCL membranes by electrospinning, the developed membranes were impregnated in a solution containing the NPs. Three different types of NPs were used: $\mathrm{Ag}, \mathrm{TiO}_{2}$ and $\mathrm{MgO}$. Ag NPs were synthesized using a green methodology described by Ferreira et al. [26], whereas commercial $\mathrm{TiO}_{2}$ and $\mathrm{MgO}$ NPs were utilized. A schematic flow chart of the whole process is represented in Figure 1.

\subsubsection{Synthesis of Ag NPs and Their Impregnation into PCL Membranes}

Ag NPs were synthetized according to a sustainable methodology described by Ferreira et al. [26], where $\mathrm{AgNO}_{3}$ was used as the precursor agent and PEG as nontoxic reducing agent, stabilizer and dispersant. Firstly, $0.04 \mathrm{M} \mathrm{AgNO}_{3}$ was dissolved in PEG 
under constant stirring for $2 \mathrm{~h}$ at room temperature (RT). The color change of the solution to yellow indicates the reduction of $\mathrm{Ag}$ ions to $\mathrm{Ag}$ metal $\left(\mathrm{Ag}^{0}\right)$, thus demonstrating the formation of NPs. Afterwards, the solution was placed in an ultrasound bath for $1 \mathrm{~h}$. After this, PCL electrospun membranes were immersed in this solution under orbital agitation for $1 \mathrm{~h}$ at RT. The membranes were removed from the impregnation solution and dried at RT. Subsequently, PCL/Ag NPs membranes were washed with distilled water at $50 \mathrm{rpm}$ for $5 \mathrm{~min}$, to remove the superficial excess of NPs.

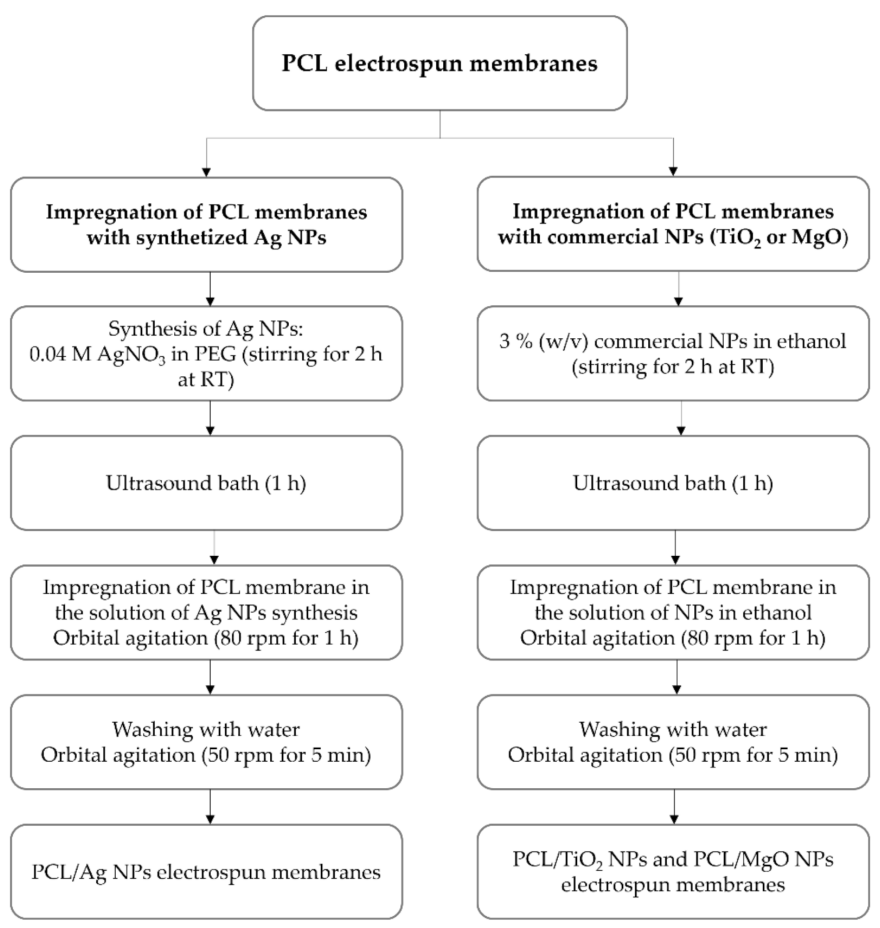

Figure 1. Schematic flow chart showing the functionalization of PCL electrospun membranes with (left) synthetized Ag NPs and (right) commercial $\mathrm{NPs}_{(\mathrm{TiO}}$ and $\left.\mathrm{MgO}\right)$.

\subsubsection{Impregnation of $\mathrm{TiO}_{2}$ and $\mathrm{MgO}$ NPs into PCL Membranes}

The impregnation solutions were prepared by adding 3\%(w/v) of each type of NPs, $\mathrm{TiO}_{2}$ and $\mathrm{MgO}$, in ethanol. Next, the solutions were placed in an ultrasound bath for $1 \mathrm{~h}$. Subsequently, the PCL electrospun membranes were immersed into the impregnation solution containing the NPs and stirred in an orbital shaker at $80 \mathrm{rpm}$ for $1 \mathrm{~h}$. The PCL membranes were allowed to dry at RT overnight, followed by washing with distilled water at $50 \mathrm{rpm}$ for $5 \mathrm{~min}$.

\subsection{Characterization of Electrospun Membranes}

\subsubsection{Field Emission Scanning Electron Microscopy (FESEM) and Energy Dispersive} Spectroscopy (EDS)

The morphology of the developed electrospun fibers as well as the presence and distribution of NPs onto them were evaluated by FESEM, using NOVA 200 Nano SEM, FEI Company (Hillsboro, OR, USA). The electrospun membranes were removed from the aluminum foil and coated with a very thin film $(20 \mathrm{~nm})$ of Au-Pd (80-20 weight\%), using a high-resolution sputter coater, 208 HR Cressington Company (Watford, UK), coupled to a MTM-20 Cressington High Resolution Thickness Controller. Secondary electron images, i.e., topographic images, were performed at acceleration voltage of $10 \mathrm{kV}$. The FESEM images were analyzed and the diameters of fibers were determined using Image J 1.53a software (Wayne Rasband-National Institutes of Health, USA), through the measurement in 100 different locations. The EDS technique (Hillsboro, OR, USA) coupled to FESEM was 
also performed to evaluate the elemental composition of the samples, using an EDAX $\mathrm{Si}$ (Li) detector with $15 \mathrm{kV}$ of acceleration voltage.

\subsubsection{Attenuated Total Reflectance-Fourier Transform Infrared Spectroscopy (ATR-FTIR)}

Chemical composition of electrospun membranes was evaluated by ATR-FTIR analysis using an IRAffinity-S1, SHIMADZU equipment (Kyoto, Japan). Each spectrum was obtained in transmittance mode, by accumulation of 45 scanning cycles and with a resolution of $8 \mathrm{~cm}^{-1}$, in a range between 400 and $4000 \mathrm{~cm}^{-1}$.

\subsubsection{Ground State Diffuse Reflectance (GSDR)}

To verify the formation and the presence of $\mathrm{Ag}, \mathrm{TiO}_{2}$ and $\mathrm{MgO}$ NPs onto the PCL membranes, GSDR analysis was performed using a Spectrophotometer UV-2600 Shimadzu. The samples were analyzed in different places to ensure homogeneity. The reflectance spectra were acquired in the range of $200-800 \mathrm{~nm}$, and the remission function $(F(R))$ was calculated accordingly with the Kubelka-Munk equation:

$$
F(R)=\frac{(1-R)^{2}}{2 R}=\frac{K}{S}
$$

where $R$ is the reflectance, $K$ is the absorption coefficient and $S$ is the dispersion coefficient [27].

\subsubsection{Thermogravimetric Analysis (TGA)}

TGA analysis was performed using a STA 700 SCANSCI (Tokyo, Japan), in order to estimate the quantity of NPs presented in each sample. The electrospun membranes were subjected to a heating process from 25 to $600{ }^{\circ} \mathrm{C}$, under nitrogen atmosphere, with a constant heating rate of $10^{\circ} \mathrm{C} / \mathrm{min}$. The percentage of NPs was calculated according to the system of equations [28]:

$$
\left\{\begin{array}{c}
\text { NPs } \%+\text { PCL membrane } \%\left(\frac{\text { PCL membrane residues } \%}{100}\right)=\text { sample total residues } \% \\
\text { NPs } \%+\text { PCL membrane } \%=100 \%
\end{array}\right.
$$

Considering that the NPs have residues of $100 \%$ and the sample with NPs after thermal treatment is composed of NPs and PCL membrane residue.

\subsubsection{Thickness}

The samples' thickness was measured using a digital caliper. Three different positions of each electrospun membranes were recorded and the average thickness was determined.

\subsection{Functional Properties Evaluation}

\subsubsection{Antibacterial Activity}

The antibacterial activity of electrospun membranes was assessed through the halo inhibition method. The inoculum was prepared by adding in a sterile medium a portion of the bacterium Staphylococcus aureus ATCC 6538 (as representative of Gram-positive bacteria) or Escherichia coli CECT 434 (as representative of Gram-negative bacteria) to $40 \mathrm{~mL}$ of TSB (Tryptic soy broth). The bacteria grew in an orbital incubator at $37^{\circ} \mathrm{C}$, with orbital shaking at $120 \mathrm{rpm}$, overnight $(18 \mathrm{~h})$. Then, the cell suspension was adjusted to a final concentration of approximately $1 \times 10^{8} \mathrm{CFU} / \mathrm{mL}$, determined from the optical density at $620 \mathrm{~nm}$.

In the antimicrobial susceptibility test, on a Petri dish containing $15 \mathrm{~mL}$ of Plate Count Agar (PCA), $0.1 \mathrm{~mL}$ of the bacterial solution $\left(1 \times 10^{8} \mathrm{CFU} / \mathrm{mL}\right)$ was spread over the dry agar. After drying, samples of $1 \times 1 \mathrm{~cm}^{2}$ were placed in the center of each Petri dish on the agar surface and incubated at $37^{\circ} \mathrm{C}$. Measurements of the bacterial growth inhibition zone were taken after $24 \mathrm{~h}$ of incubation time. This test was repeated three times in triplicate. 


\subsubsection{Filtration Capacity}

The filtration tests were performed in a cylindrical acrylic chamber $(\varnothing=194 \mathrm{~mm} \times$ length $=400 \mathrm{~mm}$ ) developed for the controlled release of particles and mounted inside a $1 \mathrm{~m}^{3}$ negative pressure flexible isolator (Solocontainment ${ }^{\mathrm{TM}}$,Cheshire, UK), to avoid the hazardous exposition of technicians to aerosolized particles during tests. Polystyrene beads $\left(\varnothing=1 \mu \mathrm{m}\right.$, COUNT-CAL ${ }^{\mathrm{TM}}$ Count Precision Size Standards Thermo Fisher) were aerosolized using a medical nebulizer (OMRON C28P) with a flow rate of $0.5 \mathrm{~mL} / \mathrm{min}$ to obtain a final amount of particles between $1 \times 10^{6}$ and $4 \times 10^{6}$ inside the aerosolization compartment of the acrylic chamber. The number of particles were measured in real time using a laser particle counter (APEX R4 airborne particle counter, Lighthouse ${ }^{\mathrm{TM}}$, Fremont, CA, USA) installed above the aerosolization compartment of the chamber. The testing membranes were mounted in a leak tight sample port positioned above the aerosolization compartment and inside the counting compartment of the acrylic chamber, where the inlet of the laser particle counter was installed. Polystyrene particles released inside the aerosolization compartment were aspirated through the sample port at a rate of $28.2 \mathrm{~L} / \mathrm{min}$ and measured three times during $20 \mathrm{~s}$ for a total of $60 \mathrm{~s}$. The acrylic chamber was cleaned between tests using a HEPA vacuum cleaner (KARCHER ${ }^{\mathrm{TM}}$ A2204, Winnenden, Germany) and the cutoff value to consider the chamber clean for tests was below 4000 particles. A blank measurement between cleaning procedures and sample loading was performed, to count the residual amount of particles inside the acrylic chamber. The acrylic chamber used to perform these tests is shown in Figure 2.

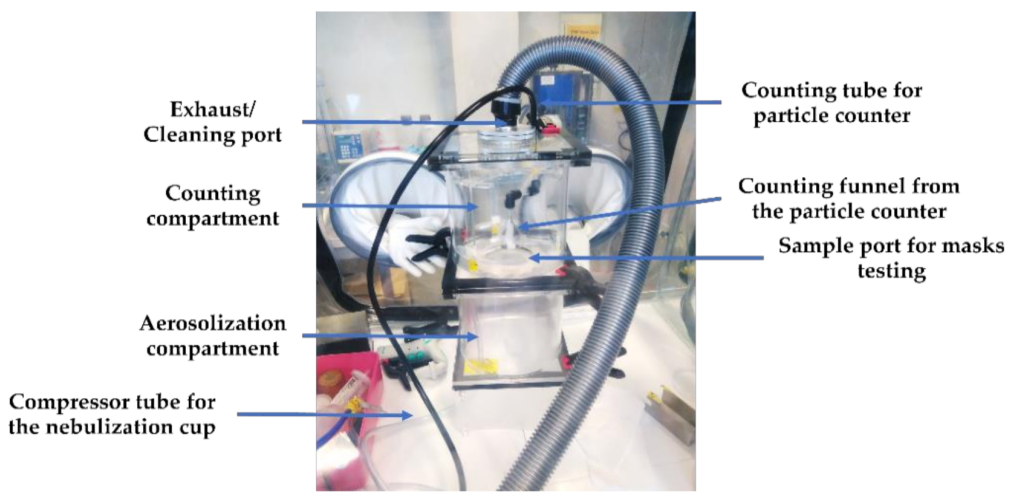

Figure 2. The different components of the acrylic chamber used for the filtration tests.

\subsubsection{Air Permeability}

The air permeability of electrospun membranes was performed by quantification of the rate of airflow through a $20 \mathrm{~cm}^{2}$ area passage at a pressure of $40 \mathrm{~Pa}$ for $1 \mathrm{~min}$, using FX3300 Air Permeabillity Tester III, TexTest instrument (WanJiang, Dongguan, China).

\subsubsection{Thermal Management}

The experiment was performed using a Thermal Imaging Camera Testo 885. The participants were tested using different facemask's prototypes: (i) Cotton + Cotton; (ii) Cotton $+\mathrm{PCL} / \mathrm{MgO}$ NPs electrospun membrane + Cotton and (iii) Cotton $+2 \times \mathrm{PCL} / \mathrm{MgO}$ NPs electrospun membrane + Cotton. Two conditions were evaluated, including during inhalation and exhalation. After an initial stabilization time, thermal images were taken and the changes in facial temperature were recorded in three different locations: nose, mouth and cheek. During the test, the participants were seated and in silence. The temperature range of the camera was defined in $24-36.5^{\circ} \mathrm{C}$. 


\section{Results and Discussion}

\subsection{Characterization of the Developed Electrospun Membranes}

3.1.1. FESEM Analysis

In order to evaluate the surface morphology and diameters of the developed electrospun fibers as well as the presence of NPs, FESEM analysis was performed (Figure 3).
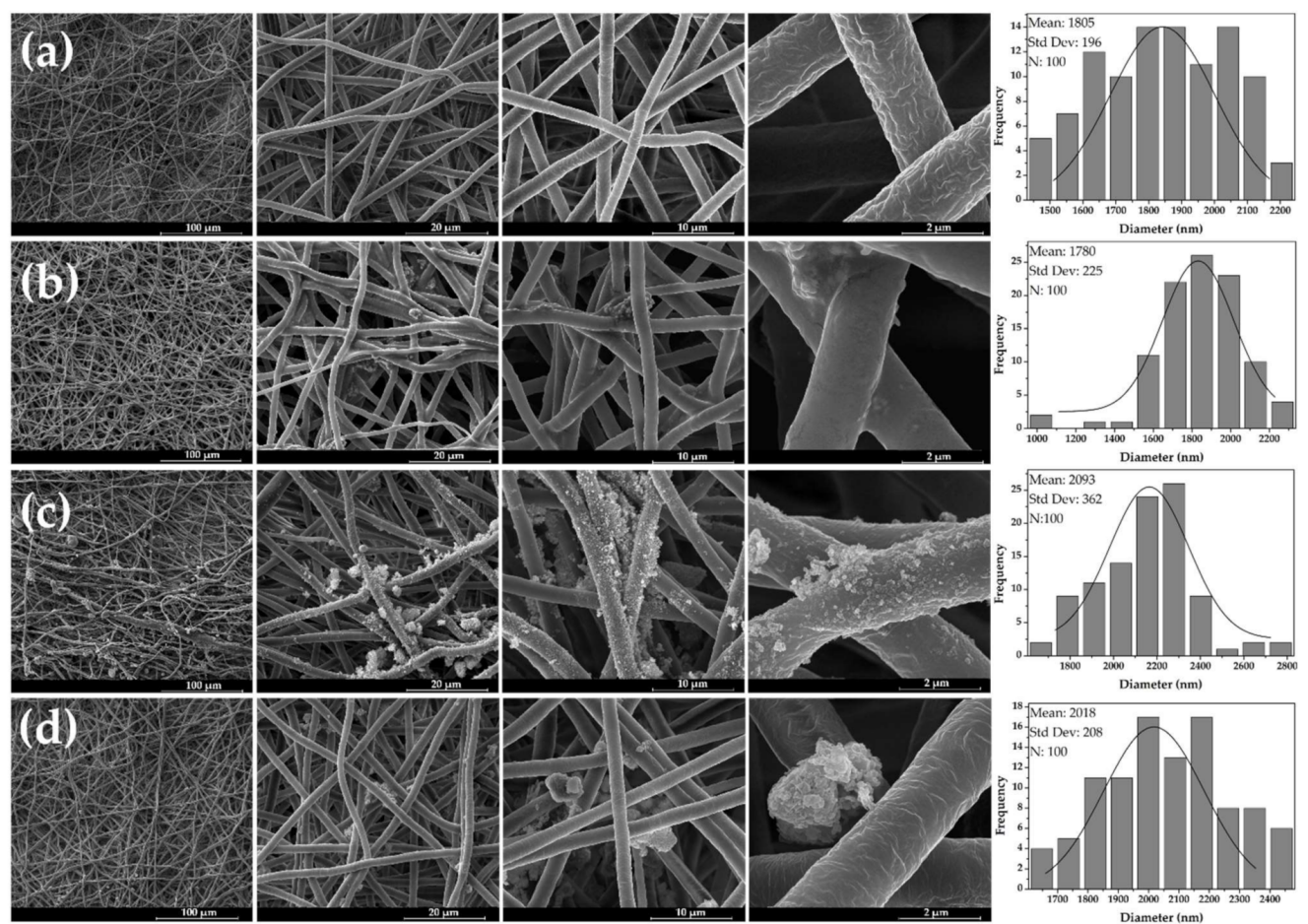

Figure 3. FESEM images of (a) PCL; (b) PCL/Ag NPs; (c) $\mathrm{PCL} / \mathrm{TiO}_{2} \mathrm{NPs}$ and (d) PCL/MgO NPs electrospun fibers and their respective diameter distribution histograms. FESEM images were obtained using different magnifications: 100, 20, 10 and $2 \mu \mathrm{m}$.

As shown in Figure 3a, defect-free PCL fibers were successfully developed with average diameters of $1.81 \mu \mathrm{m}$. Figure $3 \mathrm{~b}$ represents the PCL membranes impregnated with Ag NPs, where the presence of these NPs with some agglomerates onto the fibers is clearly visible. In this case, the $\mathrm{Ag} \mathrm{NPs}$ were synthetized through the reduction of $\mathrm{AgNO}_{3}$ by PEG, which also acted as a stabilizer and dispersing agent [26,28], this being the solution used to impregnate the PCL membranes. Thus, by these images it is possible to confirm the successful synthesis of Ag NPs as well as their attachment to the PCL electrospun membranes. A decrease in fibers' diameters was observed with the incorporation of Ag NPs $(1.78 \mu \mathrm{m})$. From Figure $3 c, d$, it is also possible to detect the presence of NPs covering the fibers' surface, which correspond to $\mathrm{TiO}_{2}$ and $\mathrm{MgO}$ NPs, respectively. Additionally, a more dense and uniform deposition was observed using $\mathrm{TiO}_{2} \mathrm{NPs}$. The impregnation with $\mathrm{TiO}_{2}$ and $\mathrm{MgO}$ NPs led to a slight increase in fibers' diameters to 2.09 and $2.02 \mu \mathrm{m}$, respectively.

\subsubsection{EDS, ATR-FTIR, GSDR and TGA Analyses}

To further confirm the synthesis of $\mathrm{Ag}$ NPs as well as the impregnation of $\mathrm{Ag}, \mathrm{TiO}_{2}$ and $\mathrm{MgO}$ NPs onto PCL electrospun membranes, other techniques, such as EDS, ATR-FTIR and GSDR were performed. Moreover, TGA was also used to quantify the amount of NPs present in each sample. The results are shown in Figure 4. 

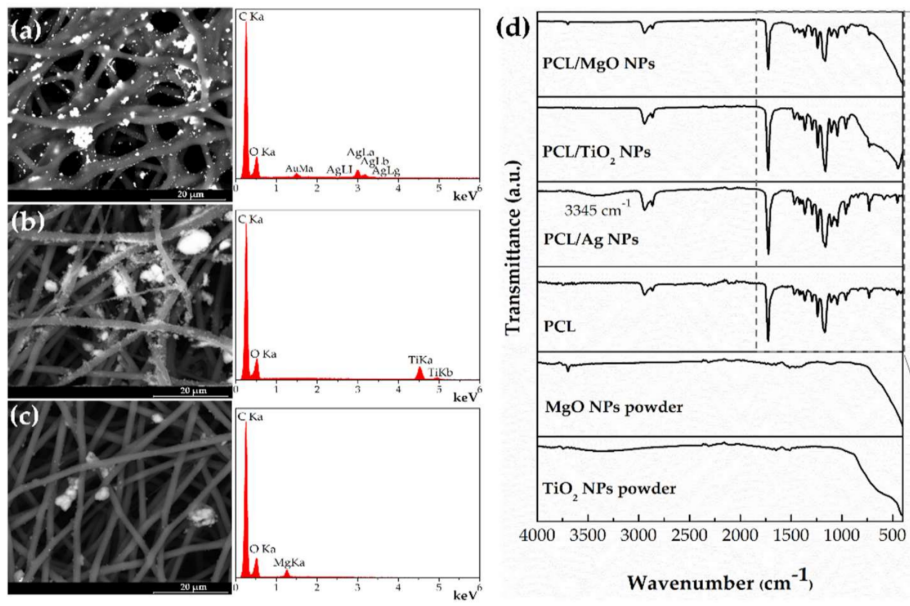

Wavenumber $\left(\mathrm{cm}^{-1}\right.$ )
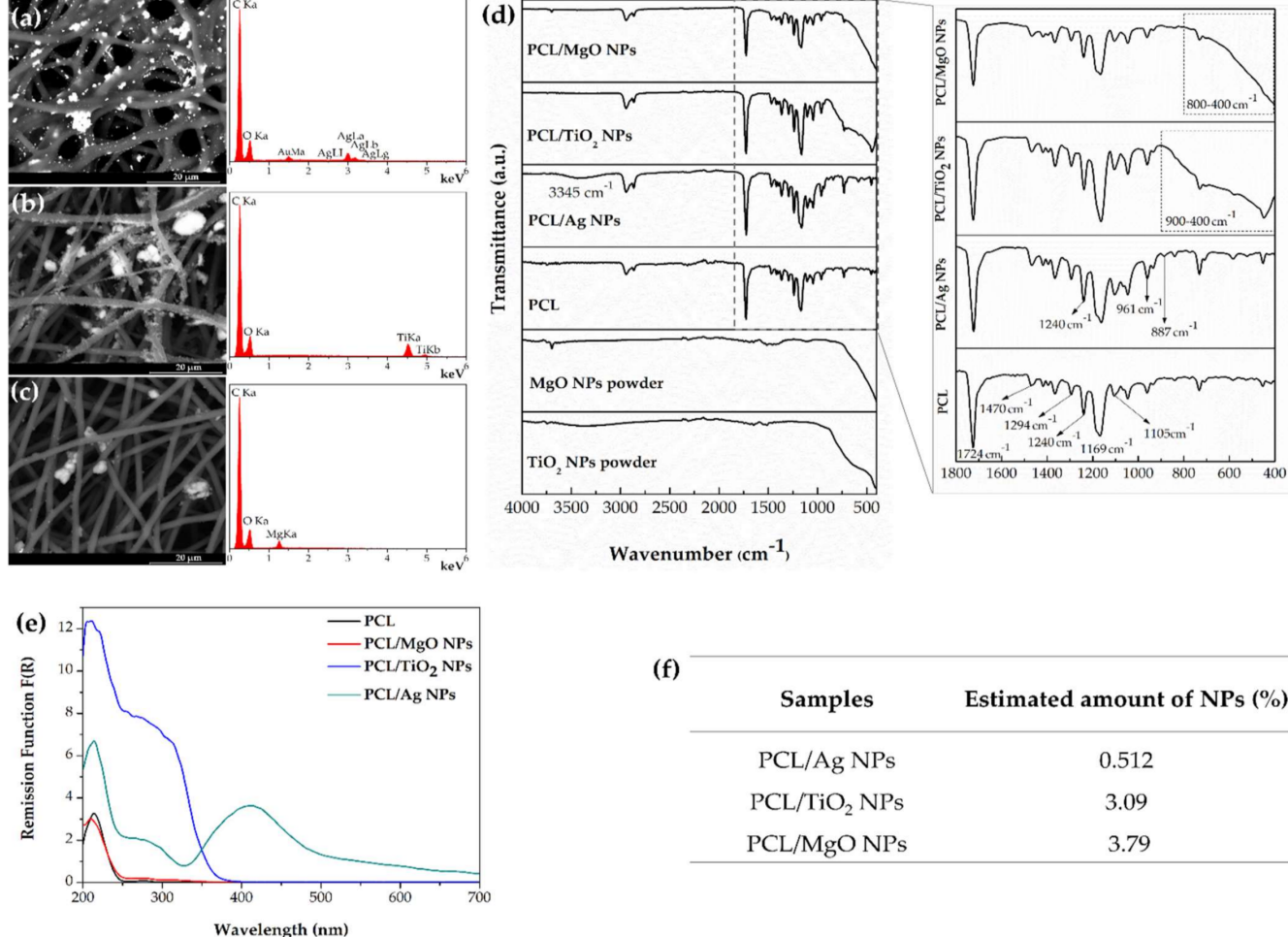

(f)

\begin{tabular}{cc}
\hline Samples & Estimated amount of NPs (\%) \\
\hline PCL/Ag NPs & 0.512 \\
$\mathrm{PCL} / \mathrm{TiO}_{2} \mathrm{NPs}$ & 3.09 \\
$\mathrm{PCL} / \mathrm{MgO} \mathrm{NPs}$ & 3.79 \\
\hline
\end{tabular}

Figure 4. EDS analysis of (a) PCL/Ag NPs; (b) $\mathrm{PCL} / \mathrm{TiO}_{2} \mathrm{NPs}$; (c) PCL/MgO NPs electrospun membranes; (d) ATR-FTIR; (e) GSDR of PCL and PCL/NPs electrospun membranes; (f) estimated amount of NPs presented in PCL membranes.

The successful impregnation of the NPs onto the surface of PCL membranes was further confirmed by EDS analysis. Figure 4e shows the presence of peaks related to carbon and oxygen, which are the constituent elements of PCL polymer. An additional strong peak appeared at $2.98 \mathrm{keV}$, which corresponds to silver, confirming the successfully synthesis and impregnation of Ag NPs on PCL fibers' surface [26,28]. The EDS spectrum from Figure $4 \mathrm{~b}$ demonstrates the characteristic peaks of titanium element at 4.51 and $4.94 \mathrm{keV}$, which together with the presence of oxygen element confirms the presence of $\mathrm{TiO}_{2}$ NPs $[29,30]$. Finally, the presence of oxygen and magnesium was detected in EDS profile of $\mathrm{PCL} / \mathrm{MgO}$ NPs membranes at 0.52 and $1.27 \mathrm{keV}$, respectively, indicating the presence of $\mathrm{MgO}$ NPs [31,32].

Regarding the ATR-FTIR analysis, PCL spectrum shows the typical bands of this polymer, with the main ones described as follows. The bands at 2941 and $2866 \mathrm{~cm}^{-1}$ correspond to the asymmetric and symmetric $\mathrm{CH}_{2}$ stretching, respectively. A strong band at $1724 \mathrm{~cm}^{-1}$ is related with carbonyl $(\mathrm{C}=\mathrm{O})$ stretching. Finally, the bands at 1470,1240 and $1169 \mathrm{~cm}^{-1}$ are attributed to $\mathrm{C}-\mathrm{C}$ bending, asymmetric $\mathrm{C}-\mathrm{O}-\mathrm{C}$ stretching and symmetric $\mathrm{C}-\mathrm{O}-\mathrm{C}$ stretching, respectively. The band at $1294 \mathrm{~cm}^{-1}$ is from $\mathrm{C}-\mathrm{O}$ and $\mathrm{C}-\mathrm{C}$ stretching in the crystalline phase, while the one at $1105 \mathrm{~cm}^{-1}$ corresponds to $C-O$ and $C-C$ stretching in the amorphous phase $[33,34]$. Considering the spectrum of PCL membranes functionalized with PEG-coated Ag NPs, besides the characteristic bands of PCL, the appearance of a new one at $887 \mathrm{~cm}^{-1}$ is observed, which is attributed to PEG polymer [26,28]. Other typical bands of PEG coincide with the region of characteristic bands of PCL, and only detect an increase in bands' intensity (1240 and $\left.961 \mathrm{~cm}^{-1}\right)$. Moreover, in the spectrum of PCL membranes with Ag-PEG NPs, a broad peak appeared at $3435 \mathrm{~cm}^{-1}$, which is attributed to stretching vibrations of O-H. This could be due to hydroxyl groups of PEG [35], or could indicate intermolecular hydrogen bonding formed between the groups from PCL and the hydroxyl groups from PEG [26]. 
The spectrum of $\mathrm{TiO}_{2}$ powder shows a characteristic band in the region of $900-400 \mathrm{~cm}^{-1}$, which is attributed to Ti-O stretching vibration. Besides presenting the typical bands of $\mathrm{PCL}$, the $\mathrm{PCL} / \mathrm{TiO}_{2} \mathrm{NPs}$ spectrum also demonstrates the presence of a new band in this region, confirming successful incorporation of $\mathrm{TiO}_{2} \mathrm{NPs}$ onto PCL membranes $[36,37]$. The spectrum of commercial MgO NPs shows a band around $800-400 \mathrm{~cm}^{-1}$, which corresponds to $\mathrm{Mg}-\mathrm{O}$ stretching vibrations [31,38-40]. The appearance of the band in the region of $800-400 \mathrm{~cm}^{-1}$ in the spectrum of PCL/MgO NPs fibers is observed, confirming the presence of these NPs into the PCL membranes' surface.

Figure 4e shows the GSDR spectra of PCL/NPs electrospun membranes. Compared to the PCL spectrum, the spectrum of PCL/Ag NPs reveals the appearance of the absorption band characteristic of Ag NPs formation, resulting from the surface plasmon resonance (SPR) of Ag NPs, peaking at $413 \mathrm{~nm}[26,28]$. This result indicates the successful synthesis and attachment of Ag NPs onto PCL membranes. On the other hand, a new absorption band at approximately $380 \mathrm{~nm}$, characteristic of $\mathrm{TiO}_{2} \mathrm{NPs}$ [41,42], is observed in the spectrum of PCL/ $/ \mathrm{TiO}_{2} \mathrm{NPs}$ membranes, once again confirming the presence of these NPs onto the PCL surface. Finally, a very small absorption band seems to appear around $277 \mathrm{~nm}$ in the spectrum of PCL/MgO NPs when compared to the PCL spectrum, which is probably related to the presence of the MgO NPs on the membranes' surfaces [43,44].

Finally, TGA analysis was performed in order to estimate the amount of NPs impregnated in PCL electrospun membranes (Figure 4f). The samples were heated to $600{ }^{\circ} \mathrm{C}$ and the residues obtained at the end of the heating process were considered, being the amount of each type of NPs calculated using equation $2[27,28]$. PCL membranes presented $2.48 \mathrm{wt} \%$ of residues while PCL/Ag NPs, PCL/ $\mathrm{TiO}_{2} \mathrm{NPs}$ and PCL/MgO NPs revealed $2.98,5.49$ and $6.18 \mathrm{wt} \%$, respectively. Assuming that the final sample is composed of PCL and NPs, the percentage of NPs presented onto the membranes' surface is approximately $0.512,3.09$ and $3.79 \%$, respectively. The estimated amount of commercial $\mathrm{NPs}\left(\mathrm{TiO}_{2}\right.$ and $\mathrm{MgO}$ ) NPs detected in PCL membranes was higher than the amount of synthetized Ag NPs. This finding could be related with the in situ synthesis of Ag NPs. Contrary to the impregnation solutions containing the commercial NPs, where the added amount of NPs is known, the impregnation solution of Ag NPs was the synthesis solution, where the amount of synthetized NPs is unknown. Since during the synthesis process some losses can occur, including the possibility of not all the precursors being reduced to produce the NPs, it is expected that the PCL/Ag NPs electrospun membranes present the lowest amount of NPs when compared to membranes containing the commercial NPs.

All of these techniques were able to confirm the successful functionalization of PCL electrospun membranes with three different types of NPs.

\subsection{Functional Properties Evaluation}

\subsubsection{Antibacterial Effect}

The antibacterial effect is a very important parameter, since the survivability of microorganisms on the facemask surface can compromise the protection of the wearer and become a source of fomite transmission. Therefore, the development of active facemasks with antibacterial properties is crucial to kill or deactivate microorganisms in addition to particle filtration [45]. The antibacterial effect was assessed by the formation of a halo around the samples, which indicates the absence of bacteria growth, the size of the halo being proportional to antibacterial effect level [28]. The antibacterial tests were performed against Gram-positive (S. aureus) and Gram-negative (E. coli) bacteria, and the results are described in Table 2.

As expected, PCL membranes did not present any antibacterial effect [46]. On the contrary, inhibition zones were formed using PCL/NPs membranes, except when using $\mathrm{PCL} / \mathrm{TiO}_{2} \mathrm{NPs}$ sample for $E$. coli. In fact, several NPs, including metal and metal oxide NPs, exhibit antibacterial effect against a broad spectrum of bacteria, the main antimicrobial mechanisms proposed being: (i) disruption of the bacterial cell membrane; (ii) generation 
of reactive oxygen species (ROS); (iii) penetration of the bacterial cell membrane and (iv) interactions with DNA, RNA, proteins and lipids, resulting in bacteria death $[18,20]$.

Table 2. Inhibition zone diameter of electrospun membranes (PCL, PCL/Ag NPs, PCL/ $\mathrm{TiO}_{2} \mathrm{NPs}_{\text {and }}$ $\mathrm{PCL} / \mathrm{MgO}$ NPs) against $S$. aureus and E. coli bacteria. Values are represented by mean \pm standard deviation of triplicates.

\begin{tabular}{ccc}
\hline \multirow{2}{*}{ Samples } & \multicolumn{2}{c}{ Mean Diameter of the Halos (mm) } \\
\cline { 2 - 3 } & S. aureus & E. coli \\
\hline PCL & $0.0 \pm 0$ & $0.0 \pm 0$ \\
$\mathrm{PCL} / \mathrm{Ag} \mathrm{NPs}$ & $18.3 \pm 0.6$ & $16.5 \pm 0.7$ \\
$\mathrm{PCL} / \mathrm{TiO}_{2} \mathrm{NPs}$ & $18.7 \pm 1.2$ & $0.0 \pm 0$ \\
$\mathrm{PCL} / \mathrm{MgO} \mathrm{NPs}$ & $25.3 \pm 0.6$ & $13.5 \pm 0.7$ \\
\hline
\end{tabular}

PCL/Ag NPs electrospun membranes exhibited an inhibition zone diameter of 18.3 and $16.5 \mathrm{~mm}$ for S. aureus and E. coli, respectively. Ag NPs are well recognized as an effective antibacterial agent [28,47]. In fact, Ag NPs can adhere to the bacterial cell membrane, altering its permeability, causing structural changes and functional damage. Moreover, $\mathrm{Ag}^{+}$ ions released from NPs can interact with intracellular components of bacteria, leading to their destruction. Ag NPs are also able to produce ROS [48]. Thomas et al. also demonstrated that PCL electrospun membranes functionalized with synthetized Ag NPs exhibited antibacterial activity against Staphylococcus epidermidis and Staphylococcus haemolyticus [46].

On the other hand, $\mathrm{PCL} / \mathrm{TiO}_{2} \mathrm{NPs}$ samples only demonstrated antibacterial effect against Gram-positive bacteria, with the size of the halo at $18.7 \mathrm{~mm}$. This is in accordance with other works, which also found that Gram-positive bacteria were more susceptible to $\mathrm{TiO}_{2} \mathrm{NPs}$ than Gram-negative, which could be due to the distinct structure of the bacteria. Gram-negative bacteria have a thin peptidoglycan layer, which is surrounded by an outer membrane layer composed by proteins, lipids and lipopolysaccharides, whereas Gram-positive bacteria present one thick peptidoglycan layer which contains a mixture of lipoteichoic acid and glucose with amino acids [30,49]. The higher amount of negatively charged peptidoglycans in Gram-positive bacteria can make them more susceptible to positively charged antimicrobials [27].

Finally, PCL/MgO NPs membranes exhibited an antibacterial effect against both S. aureus and E. coli bacteria, showing the highest inhibition zone for Gram-positive bacteria $(25.3 \mathrm{~mm})$ when compared to the other samples. Once again, the antibacterial effect was more pronounced on Gram-positive compared to Gram-negative bacteria. The main proposed mechanism of MgO NPs for bacterial lysis is the generation of ROS, which results in excessive oxidative stress, causing cell damage. The release of $\mathrm{Mg}^{2+}$ ions from NPs can also contribute to the ROS production [50]. Liu et al. showed that PCL/gelatin/MgO NPs electrospun membranes presented antibacterial effect against E. coli, S. aureus and S. epidermidis, being this effect proportional to the amount of MgO NPs incorporated [51]. Dehghan et al. also demonstrated that MgO NPs addition to polyacrylonitrile (PAN) electrospun membranes enhanced their antibacterial effect [23].

\subsubsection{Filtration Efficiency}

Filtration efficiency is one of the main concerns regarding the performance of a facemask. After the evaluation of antibacterial effect, the filtration performance of electrospun membranes was also assessed. The filtration tests were conducted in a filtration chamber using polystyrene particles of $1 \mu \mathrm{m}$ for $60 \mathrm{~s}$. The obtained results are presented in Table 3 as well as the samples' thickness and basis weight. 
Table 3. Thickness, basis weight and filtration efficiency (\%) of the different electrospun membranes (PCL, PCL/Ag NPs, PCL/ $\mathrm{TiO}_{2} \mathrm{NPs}$ and PCL/MgO NPs).

\begin{tabular}{|c|c|c|c|}
\hline Samples & $\begin{array}{l}\text { Thickness } \\
\text { (mm) }\end{array}$ & $\begin{array}{l}\text { Basis Weight } \\
\quad\left(\mathrm{g} / \mathrm{cm}^{2}\right)\end{array}$ & $\begin{array}{c}\text { Filtration Efficiency } \\
(\%)\end{array}$ \\
\hline PCL & 0.376 & 0.005 & 84.9 \\
\hline PCL/Ag NPs & 0.600 & 0.010 & 70.8 \\
\hline $\mathrm{PCL} / \mathrm{TiO}_{2} \mathrm{NPs}$ & 0.506 & 0.008 & 86.0 \\
\hline $\mathrm{PCL} / \mathrm{MgO} \mathrm{NPs}$ & 0.147 & 0.003 & 99.4 \\
\hline
\end{tabular}

PCL membranes showed a filtration efficiency of $84.9 \%$. The addition of NPs onto electrospun membranes is expected to improve their adsorption capacity, enhancing the overall filtration performance of the membranes [22,52].

Nevertheless, the introduction of Ag NPs onto PCL membranes led to a decrease in filtration efficiency to $70.8 \%$. Comparing all samples, the membranes functionalized with $\mathrm{Ag}$ NPs presented the lowest filtration efficiency. On contrary to $\mathrm{TiO}_{2}$ and $\mathrm{MgO}$ NPs, Ag NPs were synthetized, and the synthesis solution was used to impregnate PCL membranes. In fact, this result can be related with the synthesis process of these NPs, namely the amount of NPs produced and present at the membrane surface. Although the concentration of $\mathrm{AgNO}_{3}$ used was estimated to mimic the final concentration of $\mathrm{TiO}_{2}$ and $\mathrm{MgO}$ NPs used, the exact amount of synthetized Ag NPs is unknown. Since the addition of NPs onto the surface of electrospun membranes can increase the adsorption capacity of the system, contributing to the filtration performance, this could be one of the parameters that influence the filtration efficiency [22]. By TGA analysis, it is possible to have an estimation of the amount of NPs present in electrospun membranes, with the PCL/Ag NPs membrane being the one that presented the lowest amount of NPs, which corroborates these findings. Moreover, the impregnation of PCL membranes into the synthesis solution could interfere with the membrane's structure, including its integrity and pore sizes.

On the other hand, the incorporation of $\mathrm{TiO}_{2}$ and $\mathrm{MgO}$ NPs promoted an increase in filtration efficiency, presenting values of 86 and $99.4 \%$, respectively. Several parameters regulate the filtration effectiveness, such as fiber diameter, porosity and filter thickness [53]. One possible explanation is due to the changes in diameters of PCL fibers when these NPs are added. In fact, the introduction of $\mathrm{TiO}_{2} \mathrm{NPs}$ led to a slight increase in average diameters of PCL fibers from 1.81 to $2.09 \mu \mathrm{m}$, whereas the addition of MgO NPs increased the diameters to $2.02 \mu \mathrm{m}$. Consequently, a decrease in pore sizes is expected, promoting a higher filtration efficiency of the particles. Therefore, the functionalization of PCL membranes with $\mathrm{TiO}_{2}$ and $\mathrm{MgO}$ NPs was demonstrated to be a promising strategy to efficiently filtrate small particles.

Wang et al. reported that the addition of $\mathrm{TiO}_{2} \mathrm{NPs}$ into poly(lactic acid) (PLA) electrospun membranes promoted an increase in the filtration efficiency. This result could be due to the increase in nanometer-scale protrusions induced by the introduction of NPs, which can also enhance the surface roughness and specific surface area. This may dramatically increase the friction coefficient and the effective contact area between the target particles and fibers [22]. Therefore, the increase in filtration efficiency of PCL membranes functionalized with $\mathrm{TiO}_{2}$ and $\mathrm{MgO}$ NPs could be due to the increase in surface roughness and specific surface area enhancing the trapping capacity of the fibers on the particles.

Although membranes with higher thickness and basis weight are associated with higher filtration efficiency, they are also associated with higher breathing resistance [6,21]. Thus, a balance should be achieved to obtain the greatest filtration performance and breathability at the same time. In this case, the PCL/MgO NPs membranes were the ones that presented the highest filtration efficiency and the lowest thickness and basis weight, showing the advantages in using these membranes to obtain a high filtration performance without adding extra weight while maintaining the comfort. Dehghan et al. developed $\mathrm{PAN} / \mathrm{MgO}$ NPs electrospun membranes, which demonstrated high filtration efficiency and low air resistance [54]. 
Combining the results of antibacterial and filtration tests, the PCL/MgO NPs were demonstrated to be the most promising membrane, and the one selected for further tests.

\subsection{Facemask Prototype: Assembling of the Different Layers and Their Evaluation}

After selecting the best electrospun membrane to act as a filter and antibacterial layer, the assembling of the different facemask's layers was performed. Since this work aims for the development of an eco-friendly facemask, the chosen material for the inner and outer layers of the mask was a natural fabric (cotton). Three different configurations were evaluated, as exemplified in Figure 5: (i) inner and outer layers composed by cotton fabrics; (ii) inner and outer layers composed by cotton fabrics and a middle layer of $\mathrm{PCL} / \mathrm{MgO}$ NPs electrospun membrane; (iii) inner and outer layers composed by cotton fabrics and two middle layers of PCL/MgO NPs electrospun membrane.

(a)

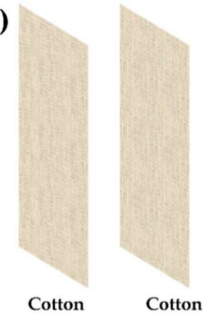

(b)

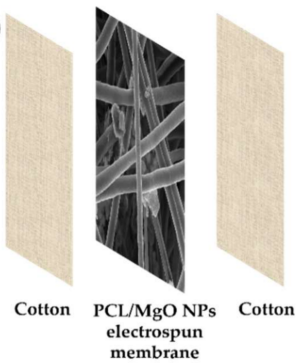

(c)

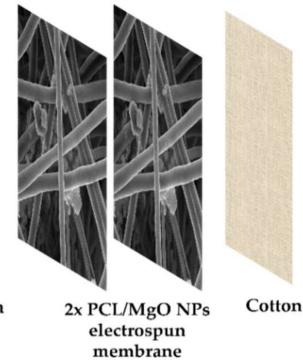

Figure 5. Schematic representation of the three configurations evaluated: (a) Cotton + Cotton; (b) Cotton + PCL/MgO NPs electrospun membrane + Cotton and (c) Cotton $+2 \times \mathrm{PCL} / \mathrm{MgO}$ NPs electrospun membrane + Cotton

Natural cellulosic fibers, such as cotton, present remarkable characteristics. Besides their natural origin, these fibers have good mechanical strength, high abundance, low cost, hydrophilicity, biocompatibility, nontoxicity, washability, reusability and provide breathability, being a suitable and sustainable option for facemasks. Moreover, cotton fabrics could be functionalized in order to achieve the required properties [3,28]. For these reasons, the facemask prototype was developed using cotton fabric for the inner and outer layers.

After the assembly of the different layers, filtration efficiency and air permeability tests were performed. The results are demonstrated in Table 4.

Table 4. Filtration efficiency $(\%)$ and air permeability $(\mathrm{L} / \mathrm{min})$ of the different facemask configurations evaluated (Cotton + Cotton, Cotton + PCL/MgO NPs electrospun membrane + Cotton and Cotton + $2 \times \mathrm{PCL} / \mathrm{MgO}$ NPs electrospun membrane + Cotton.).

\begin{tabular}{|c|c|c|}
\hline Samples & $\begin{array}{c}\text { Filtration Efficiency } \\
(\%)\end{array}$ & $\begin{array}{l}\text { Air Permeability } \\
\text { (L/min) }\end{array}$ \\
\hline Cotton + Cotton & 15.6 & 28.5 \\
\hline $\begin{array}{c}\text { Cotton }+ \text { PCL/MgO NPs electrospun } \\
\text { membrane }+ \text { Cotton }\end{array}$ & 96.2 & 3.2 \\
\hline $\begin{array}{c}\text { Cotton }+2 \times \text { PCL } / \mathrm{MgO} \text { NPs electrospun } \\
\text { membrane }+ \text { Cotton }\end{array}$ & 99.1 & 2.4 \\
\hline
\end{tabular}

As demonstrated by Table 4, the filtration efficiency of the cotton fabrics is low (15.6\%), the main aim of these layers being to act as a support for PCL/NPs electrospun membranes and to not have a significant influence on the filtration performance. The addition of electrospun membranes in the middle of the two cotton layers significantly improved the filtration efficiency, confirming that these membranes are responsible for the filtration capacity, whereas they promoted a reduction in air permeability. 
The incorporation of two PCL/MgO NPs membranes as filter layers improved the filtration efficiency from 96.2 to $99.1 \%$. Nevertheless, it decreased the air permeability of the facemask. These results were expected, since the incorporation of another filter layer composed of fibers with the same diameters and the same type and amount of NPs will promote an increase in thickness and basis weight, and consequently, a reduction in the air permeability. In fact, increasing the membranes' thickness provides more opportunities for the particles to meet with the fibers when they are traveling through the membrane [55]. Pardo-Figuerez et al. also showed that the percentage of porosity of the electrospun membranes is reduced when a higher basis weight is deposited, which can also contribute to a decrease in breathability [6].

\section{Thermal Management Using Different Facemask Prototypes}

Wearing a facemask could result in higher face temperature, leading to overall discomfort while wearing them [56]. In order to evaluate this parameter, the facial temperature changes were recorded in three different locations (nose, mouth and cheek) using the three facemask configurations. The thermal images were taken during inhalation and exhalation, as demonstrated in Figure 6.

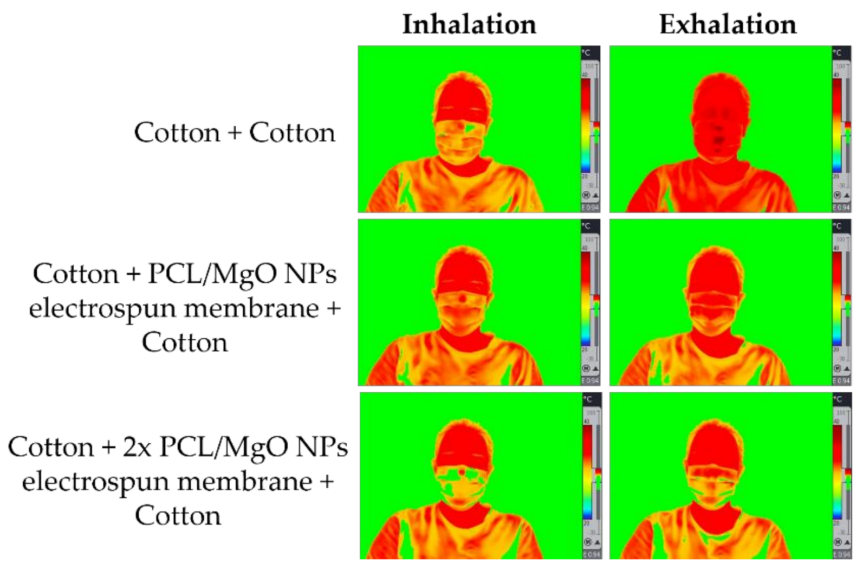

Figure 6. An example of facial temperature distribution for each condition.

As can be seen by Figure 6, the facial temperature changed according to the type of facemask used, as well as to each condition (inhalation and exhalation). During inhalation, lower temperatures were observed using Cotton $+2 \times \mathrm{PCL} / \mathrm{MgO}$ NPs electrospun membrane + Cotton, since more green and yellow areas were visible. During exhalation, higher temperatures were detected (indicated by red zones), these being the temperature values recorded in the nose, mouth and cheek (Table 5).

Table 5. Facial temperatures recorded in three different locations (nose, mouth and cheek) during exhalation using different facemask prototypes.

\begin{tabular}{cccc}
\hline \multirow{2}{*}{ Samples } & \multicolumn{3}{c}{ Facial Temperature $\left({ }^{\circ} \mathbf{C}\right)$} \\
\cline { 2 - 4 } & Nose & Mouth & Cheek \\
\hline Cotton + Cotton & 35.0 & 35.6 & 34.4 \\
\hline Cotton + PCL $/ \mathrm{MgO}$ NPs electrospun membrane + Cotton & 34.5 & 36.0 & 32.7 \\
\hline Cotton $+2 \times \mathrm{PCL} / \mathrm{MgO}$ NPs electrospun membrane + Cotton & 34.1 & 33.5 & 30.6 \\
\hline
\end{tabular}

During exhalation, facemasks composed of only cotton showed homogeneous red zones over the whole face, exhibiting temperatures between $34.4-35.6{ }^{\circ} \mathrm{C}$, which may induce slight sensations of thermal discomfort [57]. On the other hand, the incorporation of one electrospun membrane promoted a decrease in temperature in the nose and cheek, 
showing more yellow areas. Interestingly, the introduction of two electrospun membranes resulted in a reduction in temperature in the three locations (nose, mouth and check). These results demonstrated that the incorporation of electrospun membranes can improve the thermal comfort when compared to cotton-based facemasks.

\section{Conclusions}

In this work, biodegradable antibacterial PCL/NPs electrospun membranes were produced to act as a filter layer of a facemask. Defect-free PCL membranes were developed by electrospinning, showing average diameters of $1.81 \mu \mathrm{m}$. Subsequently, PCL electrospun membranes were functionalized with $\mathrm{Ag}, \mathrm{TiO}_{2}$ and $\mathrm{MgO}$ NPs, being the Ag NPs firstly synthetized using a green methodology, where PEG was used as a reducing, dispersant and stabilizing agent. The average diameters of the fibers changed to $1.78,2.09$ and $2.02 \mu \mathrm{m}$, with the impregnation of $\mathrm{Ag}, \mathrm{TiO}_{2}$ and $\mathrm{MgO}$ NPs, respectively. FESEM, EDS, ATR-FTIR and GSDR confirmed the impregnation of NPs onto PCL membranes. Moreover, TGA analysis revealed that PCL electrospun membranes contained an estimated percentage of $\mathrm{Ag}, \mathrm{TiO}_{2}$ and $\mathrm{MgO}$ NPs of $0.512,3.09$ and 3.79\%, respectively.

PCL/Ag NPs membranes exhibited an inhibition zone with diameters of $18.3 \pm 0.6$ against $S$. aureus and $16.5 \pm 0.7$ against $E$. coli, whereas $\mathrm{PCL} / \mathrm{TiO}_{2} \mathrm{NPs}$ membranes only demonstrated antibacterial effect against Gram-positive bacteria, with an inhibition zone of $18.7 \pm 1.2 \mathrm{~mm}$. Finally, PCL functionalized with MgO NPs showed halos with a size of $25.3 \pm 0.6$ and $13.5 \pm 0.7$ for $S$. aureus and E. coli bacteria, respectively, demonstrating the highest antibacterial effect against Gram-positive bacteria. The filtration performance of PCL membrane was $84.9 \%$, which reduced to $70.8 \%$ with the addition of Ag NPs. This could be due to the synthesis process of these NPs. This decrease was not observed when using commercial NPs. The impregnation of $\mathrm{TiO}_{2}$ and $\mathrm{MgO}$ NPs led to a filtration efficiency of 86.0 and $99.4 \%$, respectively. The highest filtration efficiency was detected for the membrane with the lowest thickness and basis weight (PCL/MgO NPs).

PCL/MgO NPs membranes were selected to act as the filter layer of the facemask prototypes. The addition of the filter layer in the middle of the cotton outer and inner layers significantly enhanced the filtration efficiency from 15.6 to $96.2 \%$, which increased even more with the incorporation of two electrospun membranes $(99.1 \%)$. These results were accompanied with a decrease in air permeability. Thermal management analysis revealed that the incorporation of PCL/MgO NPs electrospun membrane in the middle of the cotton layers promoted an increase in thermal comfort.

This research work reports the development of an eco-friendly active facemask. Joining the properties of electrospun membranes with the NPs, it was possible to achieve filter layers with high filtration performance and excellent antibacterial effect against both Grampositive and Gram-negative bacteria.

Author Contributions: Conceptualization, investigation, writing-original draft preparation, S.M.C.; investigation, methodology, writing - original draft preparation, L.P.; conceptualization, writingreview and editing, supervision, D.P.F.; supervision, R.F.; investigation, methodology, review and editing, P.T.; methodology, review and editing, W.A., R.V. and N.B. All authors have read and agreed to the published version of the manuscript.

Funding: The authors are thankful to project UID/CTM/00264/2021 of 2C2T-Centro de Ciência e Tecnologia Têxtil, funded by National Founds through FCT/MCTES- Fundação para a Ciência e a Tecnologia. Diana P. Ferreira is thankful to CEECIND/02803/2017 and Sofia M. Costa for the FCT PhD Scholarship (SFRH/BD/147517/2019), founded by National Founds through FCT/MCTES. Pilar Teixeira is thankful to the Portuguese Foundation for Science and Technology (FCT) under the scope of the strategic funding of UIDB/04469/2020 unit.

Institutional Review Board Statement: Not applicable.

Conflicts of Interest: The authors declare no conflict of interest. 


\section{References}

1. Fadare, O.O.; Okoffo, E.D. COVID-19 face masks: A potential source of microplastic fibers in the environment. Sci. Total Environ. 2020, 737, 140279. [CrossRef] [PubMed]

2. Das, O.; Neisiany, R.E.; Capezza, A.J.; Hedenqvist, M.S.; Försth, M.; Xu, Q.; Jiang, L.; Ji, D.; Ramakrishna, S. The need for fully bio-based facemasks to counter coronavirus outbreaks: A perspective. Sci. Total Environ. 2020, 736, 139611. [CrossRef] [PubMed]

3. Pandit, P.; Maity, S.; Singha, K.; Annu; Uzun, M.; Shekh, M.; Ahmed, S. Potential biodegradable face mask to counter environmental impact of COVID-19. Clean. Eng. Technol. 2021, 4, 100218. [CrossRef] [PubMed]

4. Lv, D.; Wang, R.; Tang, G.; Mou, Z.; Lei, J.; Han, J.; De Smedt, S.; Xiong, R.; Huang, C. Ecofriendly Electrospun Membranes Loaded with Visible-Light-Responding Nanoparticles for Multifunctional Usages: Highly Efficient Air Filtration, Dye Scavenging, and Bactericidal Activity. ACS Appl. Mater. Interfaces. 2019, 11, 12880-12889. [CrossRef]

5. Mamun, A.; Blachowicz, T.; Sabantina, L. Electrospun Nanofiber Mats for Filtering Applications-Technology, Structure and Materials. Polymers 2021, 13, 1368. [CrossRef]

6. $\quad$ Pardo-Figuerez, M.; Chiva-Flor, A.; Figueroa-Lopez, K.; Prieto, C.; Lagaron, J.M. Antimicrobial Nanofiber Based Filters for High Filtration Efficiency Respirators. Nanomaterials 2021, 11, 900. [CrossRef]

7. Qin, X.; Subianto, S. 17-Electrospun nanofibers for filtration applications. In Electrospun Nanofibers; Afshari, M., Ed.; Woodhead Publishing: Sawston, UK, 2017; pp. 449-466.

8. Graham, K.; Gogins, M.; Schreuder-Gibson, H. Incorporation of Electrospun Nanofibers into Functional Structures. Int. Nonwovens J. 2004, 13. [CrossRef]

9. Yin, X.; Zhang, Z.; Ma, H.; Venkateswaran, S.; Hsiao, B.S. Ultra-fine electrospun nanofibrous membranes for multicomponent wastewater treatment: Filtration and adsorption. Sep. Purif. Technol. 2020, 242, 116794. [CrossRef]

10. Ribeiro, A.S.; Costa, S.M.; Ferreira, D.P.; Calhelha, R.C.; Barros, L.; Stojković, D.; Soković, M.; Ferreira, I.C.F.R.; Fangueiro, R. Chitosan/nanocellulose electrospun fibers with enhanced antibacterial and antifungal activity for wound dressing applications. React. Funct. Polym. 2021, 159, 104808. [CrossRef]

11. Khandaker, M.; Progri, H.; Arasu, D.T.; Nikfarjam, S.; Shamim, N. Use of Polycaprolactone Electrospun Nanofiber Mesh in a Face Mask. Materials 2021, 14, 4272. [CrossRef]

12. Woodruff, M.A.; Hutmacher, D.W. The return of a forgotten polymer-Polycaprolactone in the 21st century. Prog. Polym. Sci. 2010, 35, 1217-1256. [CrossRef]

13. Francavilla, P.; Ferreira, D.P.; Araújo, J.C.; Fangueiro, R. Smart Fibrous Structures Produced by Electrospinning Using the Combined Effect of PCL/Graphene Nanoplatelets. Appl. Sci. 2021, 11, 1124. [CrossRef]

14. Ji, S.-M.; Tiwari, A.P.; Oh, H.J.; Kim, H.-Y. ZnO/Ag nanoparticles incorporated multifunctional parallel side by side nanofibers for air filtration with enhanced removing organic contaminants and antibacterial properties. Colloids Surfaces A Physicochem. Eng. Asp. 2021, 621, 126564. [CrossRef]

15. Nikzamir, M.; Akbarzadeh, A.; Panahi, Y. An overview on nanoparticles used in biomedicine and their cytotoxicity. J. Drug Deliv. Sci. Technol. 2021, 61, 102316. [CrossRef]

16. Araújo, J.C.; Fangueiro, R.; Ferreira, D.P. Protective Multifunctional Fibrous Systems Based on Natural Fibers and Metal Oxide Nanoparticles. Polymer 2021, 13, 2654. [CrossRef]

17. Beyth, N.; Houri-Haddad, Y.; Domb, A.; Khan, W.; Hazan, R. Alternative Antimicrobial Approach: Nano-Antimicrobial Materials. Evidence-Based Complement. Altern. Med. 2015, 2015, 246012. [CrossRef]

18. Ansari, M.A.; Albetran, H.M.; Alheshibri, M.H.; Timoumi, A.; Algarou, N.A.; Akhtar, S.; Slimani, Y.; Almessiere, M.A.; Alahmari, F.S.; Baykal, A.; et al. Synthesis of Electrospun $\mathrm{TiO}_{2}$ Nanofibers and Characterization of Their Antibacterial and Antibiofilm Potential against Gram-Positive and Gram-Negative Bacteria. Antibiotics 2020, 9, 572. [CrossRef]

19. Sánchez-López, E.; Gomes, D.; Esteruelas, G.; Bonilla, L.; Lopez-Machado, A.L.; Galindo, R.; Cano, A.; Espina, M.; Ettcheto, M.; Camins, A.; et al. Metal-Based Nanoparticles as Antimicrobial Agents: An Overview. Nanomater 2020, 10, 292. [CrossRef]

20. Wang, L.; Hu, C.; Shao, L. The antimicrobial activity of nanoparticles: Present situation and prospects for the future. Int. J. Nanomed. 2017, 12, 1227-1249. [CrossRef]

21. Bortolassi, A.C.C.; Nagarajan, S.; Araújo Lima, B.; Guerra, V.G.; Aguiar, M.L.; Huon, V.; Soussan, L.; Cornu, D.; Miele, P.; Bechelany, M. Efficient nanoparticles removal and bactericidal action of electrospun nanofibers membranes for air filtration. Mater. Sci. Eng. C. 2019, 102, 718-729. [CrossRef]

22. Wang, Z.; Pan, Z.; Wang, J.; Zhao, R. A Novel Hierarchical Structured Poly(lactic acid)/Titania Fibrous Membrane with Excellent Antibacterial Activity and Air Filtration Performance. J. Nanomater. 2016, 2016, 6272983. [CrossRef]

23. Dehghan, S.F.; Golbabaei, F.; Mousavi, T.; Mohammadi, H.; Kohneshahri, M.H.; Bakhtiari, R. Production of Nanofibers Containing Magnesium Oxide Nanoparticles for the Purpose of Bioaerosol Removal. Pollution 2020, 6, 185-196. [CrossRef]

24. Sagitha, P.; Reshmi, C.R.; Sundaran, S.P.; Sujith, A. Recent advances in post-modification strategies of polymeric electrospun membranes. Eur. Polym. J. 2018, 105, 227-249. [CrossRef]

25. Kharaghani, D.; Kee Jo, Y.; Khan, M.Q.; Jeong, Y.; Cha, H.J.; Kim, I.S. Electrospun antibacterial polyacrylonitrile nanofiber membranes functionalized with silver nanoparticles by a facile wetting method. Eur. Polym. J. 2018, 108, 69-75. [CrossRef]

26. Ferreira, D.; Ferreira, A.; Fangueiro, R. Searching for Natural Conductive Fibrous Structures via a Green Sustainable Approach Based on Jute Fibers and Silver Nanoparticles. Polymers 2018, 10, 63. [CrossRef] 
27. Araújo, J.C.; Ferreira, D.P.; Teixeira, P.; Fangueiro, R. In-situ synthesis of $\mathrm{CaO}$ and $\mathrm{SiO}_{2}$ nanoparticles onto jute fabrics: Exploring the multifunctionality. Cellulose 2021, 28, 1123-1138. [CrossRef]

28. Costa, S.M.; Ferreira, D.P.; Ferreira, A.; Vaz, F.; Fangueiro, R. Multifunctional Flax Fibres Based on the Combined Effect of Silver and Zinc Oxide (Ag/ZnO) Nanostructures. Nanomaterials 2018, 8, 1069. [CrossRef]

29. Patri, A.; Umbreit, T.; Zheng, J.; Nagashima, K.; Goering, P.; Francke-Carroll, S.; Gordon, E.; Weaver, J.; Miller, T.; Sadrieh, N.; et al. Energy dispersive $\mathrm{X}$-ray analysis of titanium dioxide nanoparticle distribution after intravenous and subcutaneous injection in mice. J. Appl. Toxicol. 2009, 29, 662-672. [CrossRef]

30. Sundrarajan, M.; Bama, K.; Bhavani, M.; Jegatheeswaran, S.; Ambika, S.; Sangili, A.; Nithya, P.; Sumathi, R. Obtaining titanium dioxide nanoparticles with spherical shape and antimicrobial properties using M. citrifolia leaves extract by hydrothermal method. J. Photochem. Photobiol. B Biol. 2017, 171, 117-124.

31. Dobrucka, R. Synthesis of MgO Nanoparticles Using Artemisia abrotanum Herba Extract and Their Antioxidant and Photocatalytic Properties. Iran. J. Sci. Technol. Trans. A Sci. 2018, 42, 547-555. [CrossRef]

32. Saied, E.; Eid, A.M.; Hassan, S.E.-D.; Salem, S.S.; Radwan, A.A.; Halawa, M.; Saleh, F.M.; Saad, H.A.; Saied, E.M.; Fouda, A. The Catalytic Activity of Biosynthesized Magnesium Oxide Nanoparticles (MgO-NPs) for Inhibiting the Growth of Pathogenic Microbes, Tanning Effluent Treatment, and Chromium Ion Removal. Catalysts 2021, 11, 821. [CrossRef]

33. Palacios Hinestroza, H.; Urena-Saborio, H.; Zurita, F.; Guerrero de León, A.A.; Sundaram, G.; Sulbarán-Rangel, B. Nanocellulose and Polycaprolactone Nanospun Composite Membranes and Their Potential for the Removal of Pollutants from Water. Mol. 2020, 25, 683. [CrossRef]

34. Nandagopal, S.; Augustine, R.; George, S.C.; Jayachandran, V.P.; Kalarikkal, N.; Thomas, S. Gentamicin Loaded Electrospun Poly( $\varepsilon$-Caprolactone) $/ \mathrm{TiO}_{2}$ Nanocomposite Membranes with Antibacterial Property against Methicillin Resistant Staphylococcus aureus. Polym. Plast. Technol. Eng. 2016, 55, 1785-1796.

35. Shameli, K.; Bin Ahmad, M.; Jazayeri, S.D.; Sedaghat, S.; Shabanzadeh, P.; Jahangirian, H.; Mahdavi, M.; Abdollahi, Y. Synthesis and Characterization of Polyethylene Glycol Mediated Silver Nanoparticles by the Green Method. Int. J. Mol. Sci. 2012, 13, 6639-6650. [CrossRef]

36. Pais, V.; Navarro, M.; Guise, C.; Martins, R.; Fangueiro, R. Hydrophobic performance of electrospun fibers functionalized with $\mathrm{TiO}_{2}$ nanoparticles. Text. Res. J. 2021. [CrossRef]

37. Al-Amin, M.; Dey, S.C.; Rashid, T.U.; Ashaduzzaman, M.; Shamsuddin, S.M. Solar Assisted Photocatalytic Degradation of Reactive Azo Dyes in Presence of Anatase Titanium Dioxide. Int. J. Latest Res. Eng. Technol. 2016, 2, $14-21$.

38. Raveesha, H.R.; Nayana, S.; Vasudha, D.R.; Begum, J.P.S.; Pratibha, S.; Ravikumara, C.R.; Dhananjaya, N. The electrochemical behavior, antifungal and cytotoxic activities of phytofabricated $\mathrm{MgO}$ nanoparticles using Withania somnifera leaf extract. J. Sci. Adv. Mater. Devices 2019, 4, 57-65. [CrossRef]

39. Fouda, A.; Hassan, S.E.-D.; Saied, E.; Hamza, M.F. Photocatalytic degradation of real textile and tannery effluent using biosynthesized magnesium oxide nanoparticles (MgO-NPs), heavy metal adsorption, phytotoxicity, and antimicrobial activity. J. Environ. Chem. Eng. 2021, 9, 105346. [CrossRef]

40. Shafiee, M.R.M.; Kargar, M.; Ghashang, M. Characterization and low-cost, green synthesis of Zn2+ doped MgO nanoparticles. Green Process. Synth. 2018, 7, 248-254. [CrossRef]

41. Kuriechen, S.K.; Murugesan, S.; Paul Raj, S. Mineralization of Azo Dye Using Combined Photo-Fenton and Photocatalytic Processes under Visible Light. J. Catal. 2013, 2013, 104019. [CrossRef]

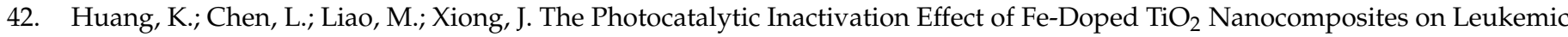
HL60 Cells-Based Photodynamic Therapy. Int. J. Photoenergy 2012, 2012, 367072. [CrossRef]

43. Das, B.; Moumita, S.; Ghosh, S.; Khan, M.I.; Indira, D.; Jayabalan, R.; Tripathy, S.K.; Mishra, A.; Balasubramanian, P. Biosynthesis of magnesium oxide $(\mathrm{MgO})$ nanoflakes by using leaf extract of Bauhinia purpurea and evaluation of its antibacterial property against Staphylococcus aureus. Mater. Sci. Eng. C. Mater. Biol. Appl. 2018, 91, 436-444. [CrossRef]

44. Almontasser, A.; Parveen, A.; Azam, A. Synthesis, Characterization and antibacterial activity of Magnesium Oxide (\{MgO $\})$ nanoparticles. IOP Conf. Ser.: Mater. Sci. Eng. 2019, 577, 12051. [CrossRef]

45. Pullangott, G.; Kannan, U.; S., G.; Kiran, D.V.; Maliyekkal, S.M. A comprehensive review on antimicrobial face masks: An emerging weapon in fighting pandemics. RSC Adv. 2021, 11, 6544-6576. [CrossRef]

46. Thomas, R.; Soumya, K.R.; Mathew, J.; Radhakrishnan, E.K. Electrospun Polycaprolactone Membrane Incorporated with Biosynthesized Silver Nanoparticles as Effective Wound Dressing Material. Appl. Biochem. Biotechnol. 2015, 176, $2213-2224$. [CrossRef]

47. Ferreira, D.P.; Costa, S.M.; Felgueiras, H.P.; Fangueiro, R. Smart and Sustainable Materials for Military Applications Based on Natural Fibres and Silver Nanoparticles. Key Eng. Mater. 2019, 812, 66-74. [CrossRef]

48. Zhang, H.; Chen, G. Potent Antibacterial Activities of Ag/ $\mathrm{TiO}_{2}$ Nanocomposite Powders Synthesized by a One-Pot Sol-Gel Method. Environ. Sci. Technol. 2009, 43, 2905-2910. [CrossRef]

49. Abu-Dalo, M.; Jaradat, A.; Albiss, B.A.; Al-Rawashdeh, N.A.F. Green synthesis of $\mathrm{TiO}_{2} \mathrm{NPs}$ / pristine pomegranate peel extract nanocomposite and its antimicrobial activity for water disinfection. J. Environ. Chem. Eng. 2019, 7, 103370. [CrossRef]

50. Bhattacharya, P.; Dey, A.; Neogi, S. An insight into the mechanism of antibacterial activity by magnesium oxide nanoparticles. J. Mater. Chem. B. 2021, 9, 5329-5339. [CrossRef] [PubMed] 
51. Liu, M.; Wang, X.; Li, H.; Xia, C.; Liu, Z.; Liu, J.; Yin, A.; Lou, X.; Wang, H.; Mo, X.; et al. Magnesium oxide-incorporated electrospun membranes inhibit bacterial infections and promote the healing process of infected wounds. J. Mater. Chem. B. 2021, 9, 3727-3744. [CrossRef] [PubMed]

52. Juuti, P.; Nikka, M.; Gunell, M.; Eerola, E.; Saarinen, J.J.; Omori, Y.; Seto, T.; Mäkelä, J.M. Fabrication of Fiber Filters with Antibacterial Properties for VOC and Particle Removal. Aerosol Air Qual. Res. 2019, 19, 1892-1899. [CrossRef]

53. Essa, W.K.; Yasin, S.A.; Saeed, I.A.; Ali, G.A.M. Nanofiber-Based Face Masks and Respirators as COVID-19 Protection: A Review. Membranes 2021, 11, 250. [CrossRef] [PubMed]

54. Dehghan, S.F.; Golbabaei, F.; Maddah, B.; Latifi, M.; Pezeshk, H.; Hasanzadeh, M.; Akbar-Khanzadeh, F. Optimization of electrospinning parameters for polyacrylonitrile-MgO nanofibers applied in air filtration. J. Air Waste Manag. Assoc. 2016, 66, 912-921. [CrossRef]

55. Li, Q.; Xu, Y.; Wei, H.; Wang, X. An electrospun polycarbonate nanofibrous membrane for high efficiency particulate matter filtration. RSC Adv. 2016, 6, 65275-65281. [CrossRef]

56. Luximon, Y.; Anne Sheen, K.; Luximon, A. Time dependent infrared thermographic evaluation of facemasks. Work 2016, 54, 825-835. [CrossRef]

57. Scarano, A.; Inchingolo, F.; Lorusso, F. Facial Skin Temperature and Discomfort When Wearing Protective Face Masks: Thermal Infrared Imaging Evaluation and Hands Moving the Mask. Int. J. Environ. Res. Public Health 2020, 17, 4624. [CrossRef] 